\title{
What it feels like to be an interesting teaching opportunity
}

\author{
Ruth Tapp describes what it feels like for the patient to be the subject of bedside teaching
}

\section{Ruth Tapp}

I was walking home one afternoon when I suddenly experienced an excruciatingly sharp pain in my chest, which got worse over the next few hours. That night I found it impossible to find a position I could sleep in-lying flat felt like my chest was being crushed in a vice. By the next morning the pain had radiated into my back, left shoulder, neck, and arm. Finally I called an ambulance.

Initially, tests focused on my heart function, which seemed to be fine, so it seemed likely I was going to be told I'd pulled a muscle, given some ibuprofen, and told to go home and lie down-if my chest $x$ ray was fine I'd be free to go.

Unfortunately it wasn't fine.

\section{A spectacular lung}

I was told I had had a complete spontaneous pneumothorax, and that my $x$ ray was "pretty spectacular." I was confused and shocked. I know the doctors didn't intend to frighten me, but the idea my lung was so damaged it was being described as spectacular terrified me. Itmade me feel that they were only interested in my body parts.

They explained they were going to insert an intercostal chest drain through my ribs to relieve the pressure. I was taken to "resus" where various bits of medical equipment were brought in and arranged around me.

I was then asked if some student doctors could observe as they had never seen a chest drain being put in place before. I didn't feel like I could say no. My situation was being described as a "great learning opportunity" and was being greeted with a sort of excitement that made me feel uncomfortable. I was starting to feel like the main attraction at some sort of freak show.

I don't want to be medically interesting to you, I thought. I just want to be ok!

\section{When consent is not consent}

I know it is really important that students learn by observing, but I felt very vulnerable. If I had been asked privately about their participation by the doctor in charge, away from the view of the waiting students, I would have said no, but I didn't get that opportunity.

I later learnt I could have removed my consent at any point during the procedure by calling "stop" and the students would have left, but this was not explained to me at the time. If I had known this, it would have reassured me greatly, as it would have given me a tiny bit of control over a very frightening and overwhelming experience.

The students themselves listened, observed, made notes, and spoke entirely to the doctor in charge, with one exception. While the doctor in charge had stepped out to prepare the chest drain, a young male student asked me how I was feeling. He sounded sincerely concerned. I said I was very scared and he replied that he could understand why but that he thought I would be ok. The doctor returned and I watched as a clear jelly-like substance was injected into my arm. I started to feel woozy as the sedative took effect.

Students on the wards can make such a difference by including us rather than just observing us. Reassure the patient yourself if your seniors haven't done it-for example, by simply stating "if at any point you'd like us to leave, just say."

I still remember that young student; he recognised that I was a feeling human being.

Competing interests: I have read and understood BMJ policy on declaration of interests and declare the following: none.

Published by the BMJ Publishing Group Limited. For permission to use (where not already granted under a licence) please go to http://group.bmj.com/group/rights-licensing/ permissions 


\section{What you need to know}

- You might view a patient's condition as unusual or interesting, but sharing that with them can make them feel very uncomfortable

- Ask your patient's permission privately before the students are in sight, give an idea of what you plan to do, and explain what to say if the patient wants to remove consent during the session

- Be sure to include the patient in the "lesson," and talk to them, not just about them 